\title{
The law as a dynamic interconnected system of states of affairs: a legal top ontology (abstract)
}

\author{
Jaap Hage Bart Verheij \\ Department of Metajuridica, Universiteit Maastricht \\ jaap.hage@metajur.unimaas.nl, bart.verheij@metajur.unimaas.nl
}

In the paper (Hage and Verheij, 1999 [4], extending Verheij and Hage, 1997 [5]), we present an abstract model of the law that is based on two crucial characteristics of the law. The first characteristic is that the law is a dynamic system of states of affairs. The law evolves over time: regulations change, contracts are signed, property rights are acquired, etc. The second characteristic is that the law is an interconnected system of states of affairs. The elements of the law are not independent of each other, but hang together in a rule-like way: stealing is punishable, the signing of a contract gives rise to obligations.

Our abstract model of the law can be regarded as a top ontology. Ontologies have recently attracted considerable interest of the field of knowledge representation in general (see, e.g., [3]) and in the field of Law and Artificial Intelligence in particular (cf., e.g., [6]). Motivations for the development of ontologies, or explicit specifications of domain conceptualizations (Gruber, 1995 [2]), include knowledge sharing and knowledge reuse (cf., e.g., [1]). Our motivation to the development of an ontology is to provide an explicit view of the legal domain with the aim to find heuristic guidelines for legal knowledge representation.

The abstract model of the law as proposed in this paper can be summarized as follows:

- The law is a system of states of affairs.

- The law is dynamic: the obtaining states of affairs are subject to change due to the occurrence of events.

- The law is interconnected: there are (directed) connections between the obtaining states of affairs based on rules.

The model uses three primitives:

- States of affairs. A state of affairs can be characterized as a possible part of the world as expressed by a (descriptive) sentence. An example is the state of affairs that the contract has been signed as expressed by the sentence 'The contract has been signed'. 
- Events. An event causes a change of the obtaining states of affairs. An example is the event of signing some contract by which the state of affairs that the contract has been signed starts to obtain.

- Rules. A rule is a directed connection between states of affairs. An example is the rule that, if the contract has been signed, obligations of the contractors towards each other emerge.

After an elaboration of the three primitives, the uses of the abstract model are illustrated by the analysis of central topics of law. This illustration of the uses of the model forms the core of the paper. We discuss the signing of a sales contract, the classification of a factual situation under a rule's conditions, kinds of rights, the role of proof and juristic acts, the validity of acts, products and rules in legislation, and the traditional classification of juristic facts in continental jurisprudence. A discussion follows of heuristic guidelines for legal knowledge representation that are suggested by the abstract model. The paper concludes with a comparison with related work. The appendix contains a formalism for the abstract model.

\section{References}

[1] Bench-Capon, T.J.M., and Visser, P.R.S. (1997). Ontologies in Legal Information Systems; The Need for Explicit Specifications of Domain Conceptualisations. The Sixth International Conference on Artificial Intelligence and Law. Proceedings of the Conference, pp. 132-141. ACM, New York (New York).

[2] Gruber, T.R. (1995). Toward principles for the design of ontologies used for knowledge sharing. International Journal of Human-Computer Studies, Vol. 43, pp. $907-928$.

[3] Guarino, N. (1995). Formal ontology, conceptual analysis and knowledge representation. International Journal of Human-Computer Studies, Vol. 43, pp. 625-640.

[4] Hage, J.C., and Verheij, B. (1999). The law as a dynamic interconnected system of states of affairs. International Journal of Human Computer Studies, Vol. 51, pp. 1043-1077.

[5] Verheij, B., and Hage, J.C. (1997). States of Affairs, Events, and Rules: an Abstract Model of the Law. Legal Knowledge Based Systems. JURIX: The Tenth Conference (eds. A. Oskamp, R.V. De Mulder, C. van Noortwijk, C.A.F.M. Grütters, K. Ashley and T. Gordon), pp. 3-20. The Foundation for Legal Knowledge Systems, Nijmegen.

[6] Visser, P.R.S., and Bench-Capon, T.J.M. (1998). A Comparison of Four Ontologies for the Design of Legal Knowledge Systems. Artificial Intelligence and Law, Vol. 6, No. 1, pp. 27-57. 